\title{
Protein p 16 as a marker of dysplastic and neoplastic alterations in cervical epithelial cells
}

\author{
Galina Volgareva*1, Larisa Zavalishina22, Yulia Andreeva², Georgy Frank², \\ Ella Krutikova ${ }^{3}$, Darya Golovina ${ }^{1}$, Alexander Bliev ${ }^{1}$, Dimitry Spitkovsky ${ }^{4}$, \\ Valeriya Ermilova ${ }^{5}$ and Fjodor Kisseljov ${ }^{1}$
}

\author{
Address: ${ }^{1}$ Institute of Carcinogenesis, N.N.Blokhin Cancer Research Center, Russian Academy of Medical Sciences, Moscow 115478 , Russia, \\ 2P.A.Gertzen Institute of Oncology, Russian Ministry of Health, Moscow 125284, Russia, ${ }^{3}$ Chair of Obstetrics and Gynecology, Ukrainian Medical \\ Stomatological Academy, Poltava, Ukraine, ${ }^{4}$ Kourion Therapeutics AG, Langenfeld, Germany and ${ }^{5}$ Institute of Clinical Oncology, N.N.Blokhin \\ Cancer Research Center, Russian Academy of Medical Sciences, Moscow 115478, Russia \\ Email: Galina Volgareva* - gmvolgareva@front.ru; Larisa Zavalishina - georgy.frank@mtu-net.ru; Yulia Andreeva - georgy.frank@mtu-net.ru; \\ Georgy Frank - georgy.frank@mtu-net.ru; Ella Krutikova - gmvolgareva@front.ru; Darya Golovina - gmvolgareva@front.ru; \\ Alexander Bliev - gmvolgareva@front.ru; Dimitry Spitkovsky - dspitkovsky@kouriontx.com; Valeriya Ermilova - gmvolgareva@front.ru; \\ Fjodor Kisseljov - f_kiss@crc.umos.ru \\ * Corresponding author
}

Published: 3I August 2004

BMC Cancer 2004, 4:58 doi:10.1 186/1471-2407-4-58

This article is available from: http://www.biomedcentral.com//47/-2407/4/58

(C) 2004 Volgareva et al; licensee BioMed Central Ltd.

This is an open-access article distributed under the terms of the Creative Commons Attribution License (http://creativecommons.org/licenses/by/2.0), which permits unrestricted use, distribution, and reproduction in any medium, provided the original work is properly cited.
Received: 17 March 2004

Accepted: 31 August 2004

\begin{abstract}
Background: Cervical carcinomas are second most frequent type of women cancer. Success in diagnostics of this disease is due to the use of Pap-test (cytological smear analysis). However Pap-test gives significant portion of both false-positive and false-negative conclusions. Amendments of the diagnostic procedure are desirable. Aetiological role of papillomaviruses in cervical cancer is established while the role of cellular gene alterations in the course of tumor progression is less clear. Several research groups including us have recently named the protein pI $6^{1 N K 4 a}$ as a possible diagnostic marker of cervical cancer. To evaluate whether the specificity of p I6 1 NK4a expression in dysplastic and neoplastic cervical epithelium is sufficient for such application we undertook a broader immunochistochemical registration of this protein with a highly pI $6^{1 N K 4 a}$-specific monoclonal antibody.

Methods: Paraffin-embedded samples of diagnostic biopsies and surgical materials were used. Control group included vaginal smears of healthy women and biopsy samples from patients with cervical ectopia. We examined 197 samples in total. Monoclonal antibody E6H4 (MTM Laboratories, Germany) was used.

Results: In control samples we did not find any p I6INK4a-positive cells. Overexpression of p I6INK4a was detected in samples of cervical dysplasia (CINs) and carcinomas. The portion of pl 6 INK4a-positive samples increased in the row: CIN I - CIN II - CIN III - invasive carcinoma. For all stages the samples were found to be heterogeneous

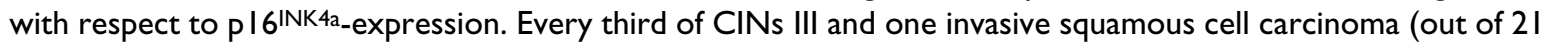
analyzed) were negative.

Conclusions: Overexpression of the protein pI $6^{1 N K 4 a}$ is typical for dysplastic and neoplastic epithelium of cervix uteri. However p I 6INK4a-negative CINs and carcinomas do exist. All stages of CINs and carcinomas analyzed are heterogeneous with respect to p 16 INK4a expression. So p 16 INK4a-negativity is not a sufficient reason to exclude a patient from the high risk group. As far as normal cervical epithelium is p I6INK4a-negative and the ratio pI6INK4a_ positive/ p/6INK4a-negative samples increases at the advanced stages application of immunohisto-/cytochemical test for p I 6 ${ }^{\mathrm{INK} 4 \mathrm{a}}$ may be regarded as a supplementary test for early diagnostics of cervical cancer.
\end{abstract}




\section{Background}

Cervical cancer makes up about $10-12 \%$ of total women cancers $[1,2]$ with the level of mortality in Russian population 5.0 per 100000 [1]. The tendency is being observed for the past decades towards reduction of both incidence and mortality. It is mainly due to the population-wide screening protocols in developed countries which allow identifying early asymptomatic forms of cervical carcinomas. However some problems remain to be solved concerning early detection of this type of cancer.

The main screening test for cervical cancer is the cytological smear staining technique developed by G. Papanicolaou [3] and known as Pap test. Despite evident success this test gives a substantial rate of both false-positive and false-negative results.

Histological analysis of a biopsy sample, more laborious in preparation and study as compared with that of a cytological smear, is also not absolutely efficient owing to a substantial rate of interobserver discrepancies among expert pathologists examining the same material [4].

Infection with human papilloma viruses (HPV) belonging to so-called high-risk group is the main risk factor of cervical cancer incidence [2]. To detect high risk HPVs in epithelial cells of a patient polymerase chain reaction (PCR) has been applied during the past two decades [5]. However this highly sensitive technique cannot resolve the problem of early cervical carcinoma detection also so far as many early stage lesions regress and epithelial dysplasia (i.e. cervical intraepithelial neoplasms, CINs) and carcinomas appear only in a minor part of the persons in whose epithelium (on a smear) high risk HPVs had been detected [2].

For the recent years several research groups [4,6-16] including us [11] have dwelt on the protein p16 ${ }^{\text {INK4a }}$ for a possible supplementary marker of dysplastic and neoplastic cervical epithelium lesions. This protein belongs to the group of cyclin-dependent kinase Cdk4/6 inhibitors [17] and is encoded by tumor suppressor gene INK $4 a$ (synonyms: MTS 1, CDKN2, INK4a/ARF). Gene INK4a plays an important role in the regulatory pathway $\mathrm{Cdk}-\mathrm{Rb}-\mathrm{E} 2 \mathrm{~F}$. The product of this gene $\mathrm{p} 16^{\mathrm{INK} 4 \mathrm{a}}$ prevents $\mathrm{pRb}$ phosphorylation by inactivating $\mathrm{Cdk} 4 / 6$; pRb keeps on binding E2F transcription factors and as a result cells stay in G1 phase not passing to DNA replication. In various tumor types INK4a as a bona fide tumor suppressor undergoes homozygous deletions, is inactivated by point mutations, LOH or hypermethylation; p16 INK4a expression is reduced or ceases under such conditions or the protein function may be impaired [18].
Peculiarity of cervical carcinomas is due to the ability of HPV oncoprotein E7 to interact with $\mathrm{pRb}$ and inactivate it [19]. As a result, the regulatory pathway Cdk-Rb-E2F is disrupted and the status of gene suppressor INK4 $a$ and its protein becomes of no importance for a cell so far as they function upstream of the site of breakage. Cells with thus inactivated pRb pass cell cycle checkpoint G1/S without any obstacle.

Reciprocallity between status of $\mathrm{pRb}$ and that of $\mathrm{p} 16^{\mathrm{INK} 4 \mathrm{a}}$ commonly found in human permanent cell lines (including cervical cell line cultures) $[17,20,21]$ as well as in primary tumor cells $[9,22,23]$ served for a logical prerequisite of utilizing $\mathrm{p} 16^{\mathrm{INK} 4 \mathrm{a}}$ protein as a marker of premalignant and malignant cervical epithelium cells. Functionally active gene $R B$ was shown to be able to negatively regulate the expression of INK4a on a transcriptional level, but details of this negative feed-back loop remain obscure [24].

To estimate the applicability of p16 $6^{\text {INK4a }}$ as a marker of dysplastic and neoplastic alterations in cervical epithelium cells we analyzed the expression of this protein utilizing a highly $\mathrm{p} 16^{\mathrm{INK} 4 \mathrm{a}}$ - specific monoclonal antibody. We examined 197 samples in total. The materials studied included: 1) samples of normal epithelium of healthy women (cytological vaginal smears), 2) diagnostic biopsy samples from patients with cervical ectopia, 3) samples of CINs of various stages, 4) samples of invasive cervical cancer, 5) samples from different normal utery body and cervix tissues from women with gynecological diseases not associated with dysplastic lesions of epithelium (diagnostic biopsies and surgical materials) and 6) samples of cells from 3 cervical carcinoma cell lines. We also compare our data with the results presented by other groups working in similar directions [4,6-10,12-16].

We demonstrate in the present work that overexpression of the protein p16 $16^{\mathrm{INK} 4 \mathrm{a}}$ is typical for some samples of dysplastic and neoplastic epithelium of cervix uteri. We have not found at least a single sample overexpressing p16 INK4a among control samples. The portion of $\mathrm{p} 16^{\mathrm{INK} 4 \mathrm{a}}$-positive samples increases in the following row: CIN I - CIN II CIN III - invasive carcinoma. However p16 $6^{\text {INK4a-negative }}$ CINs and carcinomas have also been found. All stages of CINs and carcinomas analyzed turn out to be heterogeneous with respect to p16 $16^{\text {INK4a }}$ expression: side by side with the samples which express p $16^{\text {INK4a }}$ in $25 \%$ of cells or more we detect samples which are stained poorly or lack

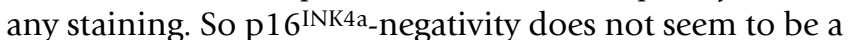
sufficient reason to exclude a patient from the high risk group when results of Pap-test, HPV detection by PCR or histological investigation warn about possibility of poor prognosis. As far as normal cervical epithelium is p16 INK4a-negative and the ratio p16 ${ }^{\text {INK4a-positive/ }}$ 
p16 INK4a-negative samples increases at the advanced stages of CINs and carcinomas application of immunohisto-/cytochemical test for $\mathrm{p} 16^{\text {INK4a }}$ may be regarded as a supplementary (optional) test for early diagnostics of cervical cancer.

\section{Methods}

Immunohisto-/immunocytochemical study was performed on 197 samples in total. Those included 6 samples from normal epithelium of healthy women (cytological vaginal smears taken during regular examination), as well as the following surgical and diagnostic biopsy materials: 37 samples from patients with cervical ectopia, 113 samples of CINs of different stages including cancer in situ, 26 samples of invasive cervical cancer (21 squamous cell carcinomas and 5 adenocarcinomas), 12 samples of normal tissues from uterus body (myometrium) and cervix from patients with different gynecological diseases, 3 cervical cell line samples taken for positive control (see below). Apart from 9 smears (which included 6 samples from healthy women and 3 samples taken from cell cultures which served as controls) the rest 188 materials were paraffin-embedded histological blocks. The quality of smears turned out to be satisfactory for immunochemical analysis (Fig. 1a and 1d).

Neutral formalin-fixed paraffin embedded samples of biopsies and surgery materials were received from archives of N.N.Blokhin Cancer Research Center (Moscow), P.A. Gertzen Institute of Oncology (Moscow), Central Clinical Hospital (Moscow) and Fourth Clinical Hospital (Poltava, Ukraine).

For immunohistochemical analysis $4-5 \mu \mathrm{m}$ serial sections were transferred on Histobond slides with adhesive layer (SMT Geraetehandel GmbH, Germany). The first section was stained with hematoxylin-eosin for traditional morphological analysis and verification of diagnosis by not less than two independent pathomorphologists.

Presence of high risk HPV in cervical CIN and carcinoma cells was verified by PCR [25]. Some of the squamous cell carcinomas were tested by Southern blot hybridization in addition to PCR. The results of both methods coincided completely. To detect high-risk HPV in adenocarcinomas Hybrid Capture 2 test (enabling to detect but not to discern HPV 16 and HPV 18) was used. The following portions of samples (out of those studied immunochemically) were analysed for high-risk HPV genetic material: CINs I - 9/51, CINs II - 9/32, CINs III $19 / 24$, invasive squamous cell carcinomas - $21 / 21$, adenocarcinomas - 5/5. This study did not cover all CINs which we studied immunochemically due to the tiny size of most of those samples.
Vaginal normal epithelium smears obtained during regular examination from healthy women were transferred on HistoBond slides. Absence of abnormal cells was confirmed in Cytology Department of Cancer Research Center on a parallel slide. Smears were fixed for $5 \mathrm{~min}$ in $10 \%$ formaldehyde, washed with flowing water, and processed for further development as described for deparaffinized histological slices [9]. Cells of cervical cell lines were cultured under standard conditions in DMEM supplemented with $10 \%$ of foetal bovine serum. For immunocytochemistry cells were taken during culture receeding, dropped in a culture medium on a Histobond slide, airdried and then processed identically to smears from healthy women.

Immunohistochemical staining was carried out using p16 ${ }^{\text {INK4a }}$-specific monoclonal antibodies E6H4 (MTM Laboratories AG, Germany) according to protocol by Klaes et al [9].

\section{Controls in the course of immunohistochemical studies were as follows}

Positive controls

1). In the beginning of the study as a whole cells of three cervical cell lines were stained first. They were SiHa (HPV16-positive), C33a and HT-3 (both HPV-negative); all of them had been characterized as expressing the protein p16 $6^{\text {INK4a }}$ in earlier immunocytochemical studies with the same antibody [9]. 2). One HT-3 cell slide was stained in parallels with the first series of biopsy materials. 3). Every next group of slides intended for staining compulsorily included the slide with one of the serial sections of the CINIII or invasive carcinoma sample which had been characterized as a $16^{\mathrm{INK} 4 \mathrm{a}}$-positive one in our previous studies (on preceeding cuts). The analysis of the given slide series was carried out only if the positivity of the control sample was confirmed. Thus neither slide series in the present study was completely p $16^{\text {INK4a-negative. }}$

\section{Negative controls}

1). One more serial cut made from p16 $6^{\mathrm{INK} 4 \mathrm{a}}$-expressing material was included into every slide series meant for staining (as in variant 3 of positive controls, - see above) which was processed in a usual way but PBS was applied instead of p16 ${ }^{\text {INK4a }}$-specific antibody. The results were regarded as valid if this slide was negative. 2). As an intrinsic negative control served adjacent to CIN or carcinoma normal tissues including stromal elements. In neither case did we find any staining in these tissues (fig. 1c).

In addition to four categories of staining defined by Klaes et al. [9],- poor (less than $1 \%$ of stained cells,- figure $1 \mathrm{~b}$ ), sporadic (1-5\% of stained cells, - figure 1b), focal (cell clusters were stained but not more than $25 \%$ of cells were positive, - figure 2a) and diffuse (more than $25 \%$ of cells 

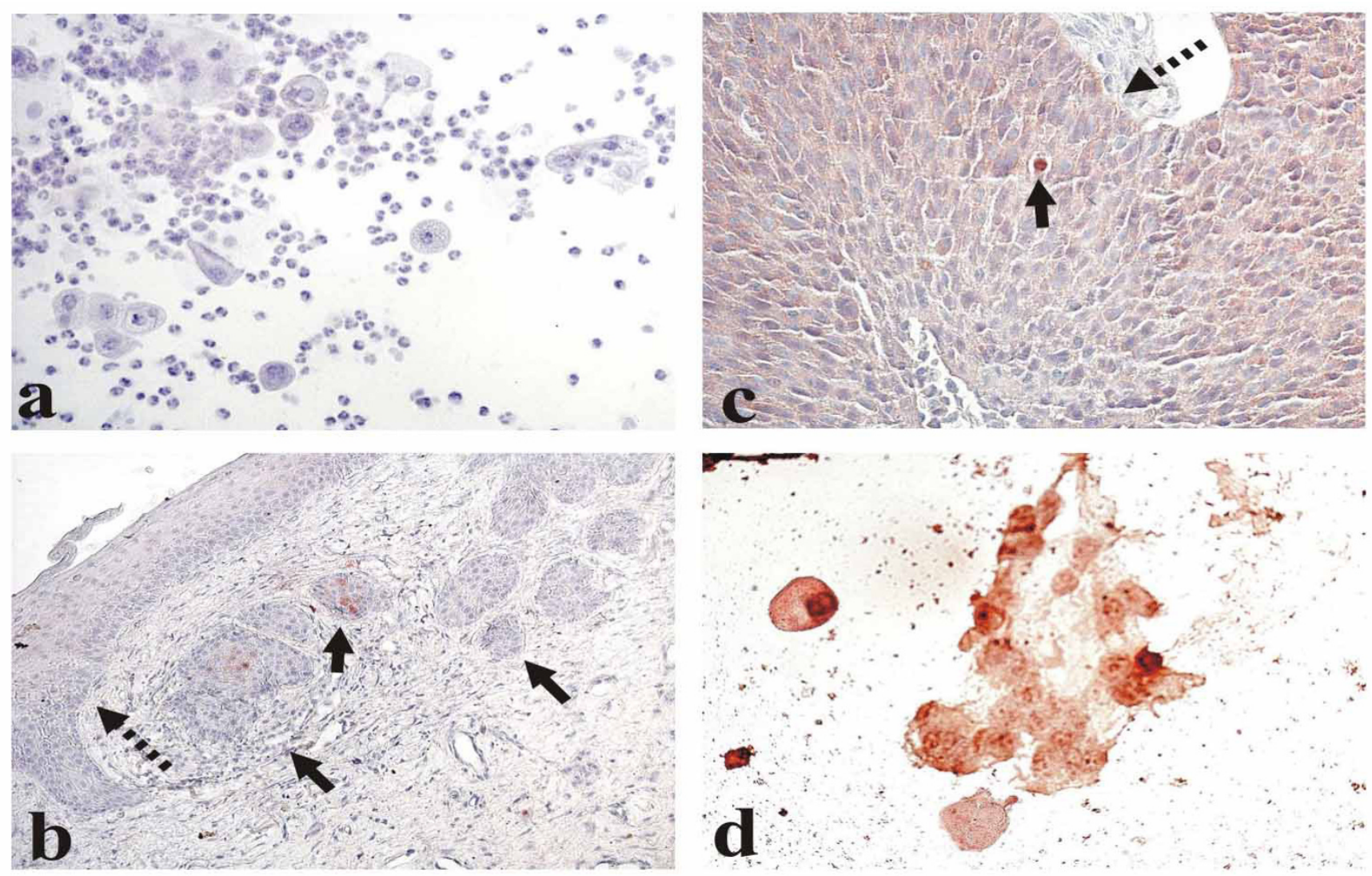

\section{Figure I}

Different types of cervical cell staining with the pI6INK4a-specific antibodies. a. Normal epithelium (smear): negative staining. b. CIN I (indicated with a dotted arrow) and cancer in situ (solid arrows): a very poor cytoplasmic staining in separate CIN I cells and sporadic staining in cancer in situ. c. Invasive squamous cell carcinoma. Diffuse cytoplasmic staining with the sole cell expressing p I6INK4a in the nucleus (solid arrow). The boundary with adjoining normal tissue is marked with a dotted arrow. $d$. HT3 cells (smear) with both nuclear and cytoplasmic subcellular location of the positive staining.

were stained, - figures $1 \mathrm{c}$ and $2 \mathrm{c}, 2 \mathrm{f}, 2 \mathrm{~g}, 2 \mathrm{~h})$, we formed one more group (negative) of those samples which totally lacked any stained cells (Figures $1 \mathrm{a}, 2 \mathrm{~b}, 2 \mathrm{~d}$ and $2 \mathrm{e}$ ). We regarded those cells as stained in which p161NK4a was expressed in nuclei and/or in a cytoplasm.

\section{Results}

Various types of p16 INK4a-specific staining of cervix uteri normal, dysplastic and cancer cells are presented in Fig. 1a, 1b,1c,1d and Fig. 2a, 2b,2c,2d,2e,2f,2g,2h.

We did not register any staining in either of 6 smear samples taken from healthy women (Fig. 1a). An example of a very poor cytoplasmic staining in some separate CIN I cells with a more pronounced (sporadic, both nuclear and cytoplasmic) staining in the adjacent cancer in situ cells is shown in Fig. 1b. In one invasive carcinoma we detected cytoplasmic staining in the predominant majority of cancer cells while but sole nuclei turned out to be stained
(Fig. 1c); the boundary between cancer and normal tissues coincided with the line at which the staining discontinued. As to the cervical cells cultivated in vitro taken for positive controls, in HT-3 cells the specific staining was strongly manifested both in nuclei and in a cytoplasm (Fig. 1d) while in SiHa and C33a cells it was exclusively cytoplasmic. It is not clear yet why in one and the same cervical cancer sample the protein p16 ${ }^{\mathrm{INK} 4 \mathrm{a}}$ (normally showing its activity in nuclei) may be detected but in a cytoplasm in the majority of cells while in a number of cells both in nuclei and cytoplasm, why in some cervical cell cultures it is found solely in cytoplasm and in other cervical cell lines - in nuclei also. We did not find at least a single sample with an exceptionally nuclear staining; similar were the results by other investigators [9]. With keeping in mind that subcellular location of p16 $6^{\text {INK4a }}$-specific staining varies to such a degree we scored as positive every sample in which the staining was expressed either in a cytoplasm or in both nuclei and cytoplasm. 

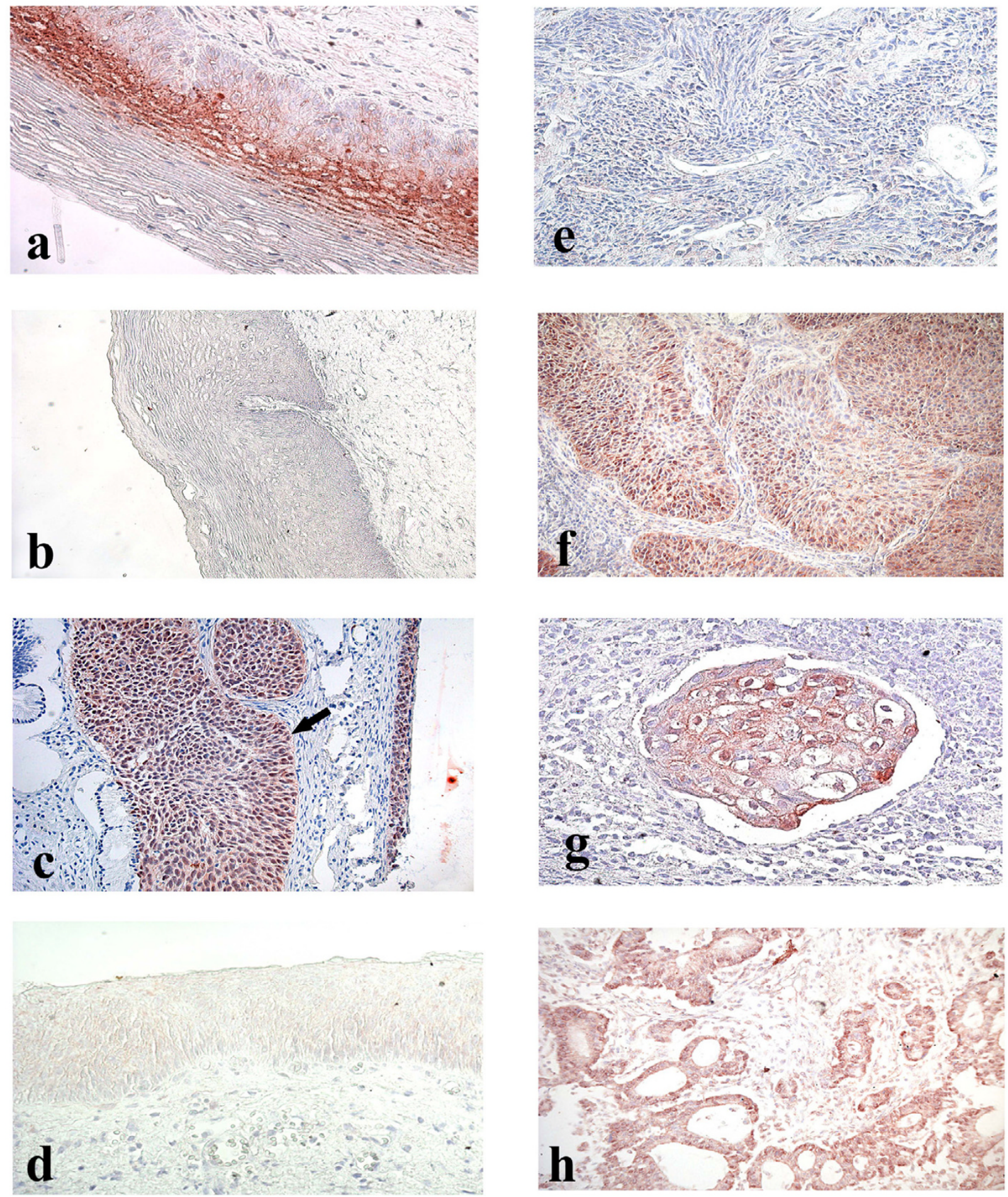

Figure 2

Cervical tissue samples after immunohistochemical staining with p I6INK4a-specific antibodies. a. CIN I. Focal staining. b. CIN II. Negative staining. c. Cancer in situ (indicated with an arrow) and CIN III. Diffuse staining. d. CIN III. Negative staining. e. Squamous cell carcinoma. Negative staining. f. Squamous cell carcinoma. Diffuse staining. g. Squamous cell carcinoma embol. Diffuse staining. h. Adenocarcinoma. Diffuse staining. 
Table I: pI6INK4a EXPRESSION IN NORMAL, DYSPLASTIC AND NEOPLASTIC EPITHELIAL CELLS OF CERVIX UTERI

\begin{tabular}{|c|c|c|c|c|c|c|}
\hline \multirow[b]{2}{*}{ MATERIALS } & \multirow[b]{2}{*}{ number of samples } & \multicolumn{5}{|c|}{ STAINING* } \\
\hline & & negative & poor & sporadic & focal & diffuse \\
\hline Normal epithelium (smears) & 6 & $6(100)$ & - & - & - & - \\
\hline Cervical ectopia including & 37 & $34(91,9)$ & $3(8,1)$ & - & - & - \\
\hline C.e. + coilocytosis & 10 & 9 & 1 & - & - & - \\
\hline C.e. + condyloma & 2 & 1 & 1 & - & - & - \\
\hline \multicolumn{7}{|l|}{ Dysplasia: } \\
\hline CINs I & 51 & $32(62,7)$ & $12(23,5)$ & $6(11,8)$ & $I(2,0)$ & - \\
\hline CINs II & 38 & $26(68,4)$ & $7(18,4)$ & $4(10,5)$ & $\mathrm{I}(2,7)$ & - \\
\hline CINs III including cancer in situ & 24 & $8(33,3)$ & $3(12,5)$ & $7(29,2)$ & $2(8,3)$ & $4(16,7)$ \\
\hline $\begin{array}{l}\text { Invasive carcinomas including squamous cell } \\
\text { carcinomas adenocarcinomas }\end{array}$ & 26 & $\mathrm{I}(3,8)$ & I $(3,8)$ & $4(15,5)$ & $7(26,9)$ & $13(50,0)$ \\
\hline Squamous cell carcinomas & 21 & I $(4,8)$ & I $(4,8)$ & $3(14,3)$ & $6(28,5)$ & $10(47,6)$ \\
\hline Adenocarcinomas & 5 & - & - & I $(20,0)$ & I $(20,0)$ & $3(60,0)$ \\
\hline
\end{tabular}

* percent is given in parenthesis

The data of the analysis of the cervical epithelium preparations stained with monoclonal antibodies E6H4 are summarized in Table 1.

In all 37 samples from patients with cervical ectopia p16 ${ }^{\text {INK4a }}$-positive cells were observed with low frequencies: 34 samples were negative and 3 ones $(8,1 \%)$ were stained poorly.

In the group of CINs I $63 \%$ of the samples were p16INK4a negative. In 7 samples (about 14\%) sporadic or focal (Fig. 2a) type of staining was observed.

Group of CINs II turned out to be highly heterogeneous in terms of the ratio of p $16^{\text {INK4a }}$-positive cells as well. Most of these samples $(68 \%, 26$ out of 38 , Fig. 2b) did not differ from the samples of normal epithelium, but the rest 12 samples we attributed to poor, sporadic or focal types. In neither sample of CIN I or CIN II did we observe diffuse staining for $\mathrm{p} 16^{\mathrm{INK} 4 \mathrm{a}}$.

Among the samples of CIN III about 54\% (13 out of 24) were attributed to sporadic (Fig 1b), focal or diffuse (Fig. 2c) types. However every third CIN III sample was found to be p16 $6^{\text {INK4a }}$-negative (Fig. $2 \mathrm{~d}$ ).

As to invasive cancers, only 1 out of 26 samples (3.8\%) lacked p16 INK4a-positive cells (Fig. 2e). One sample expressed the marker poorly. In 24 cases sporadic, focal or diffuse staining was observed. Diffuse staining was registered in about $50 \%$ of these samples (Figs. 1c, 2f, $2 \mathrm{~g}, 2 \mathrm{~h}$ ). Among 14 samples of invasive carcinomas which had been stored in paraffin blocks for 7 years $1(7.1 \%)$ turned

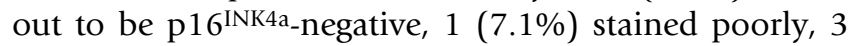

(21.4\%) stained sporadically, 4 (28.4\%)-focally and 5 (35.8\%) expressed diffuse staining.

We have examined several cases with more than one type of lesion on the same slide. Examples are presented on Figures $1 \mathrm{~b}$ and $2 \mathrm{c}$. As a rule in combined cases $\mathrm{p} 16^{\mathrm{INK} 4 \mathrm{a}}$ expression was more pronounced in cells belonging to a more advanced lesion (Fig. 1b).

All the HPV-tested samples of CINs and invasive squamous cell carcinomas were high-risk HPV-positive (data on CINs I and CINs II are shown in the additional file, results with CINs III and squamous cell carcinomas - in Table 2). High-risk HPVs were also found in all the samples of adenocarcinomas.

In reference group composed of samples from normal uterus body and cervix uteri tissues obtained from patients with gynecological diseases (stromal and glandular tissues of the cervix from patients with cervical ectopia from which squamous cell epithelium had been fully cut off; myometrium of uterus body from the patient after surgery for cervical carcinoma) the results of staining with p16 ${ }^{\text {INK4a }}$-specific antibodies were negative in all 12 cases (Table 3).

\section{Discussion}

Immunochemical detection of $\mathrm{p} 16^{\mathrm{INK} 4 \mathrm{a}}$ by monoclonal antibodies shows that the overwhelming majority of invasive cervical carcinoma samples differ from normal cervical epithelium of healthy women. We found no cases of sporadic, focal or diffuse staining with $\mathrm{E} 6 \mathrm{H} 4$ antibodies among 6 vaginal smears from healthy women as well as among 37 samples from patients with cervical ectopia including those in which ectopically localized cervical epi- 
Table 2: Data on high risk HPV genome detection by PCR in CIN III and invasive squamous cell carcinoma samples

\begin{tabular}{|c|c|c|}
\hline Sample No & Type of immunochemical staining & HPV type \\
\hline \multicolumn{3}{|c|}{ CINs III } \\
\hline I & negative & 16 \\
\hline 2 & negative & 18 \\
\hline 3 & negative & 16 \\
\hline 4 & poor & 16 \\
\hline 5 & poor & 16 \\
\hline 6 & poor & 16 \\
\hline 7 & sporadic & 16 \\
\hline 8 & sporadic & 16 \\
\hline 9 & sporadic & 16 \\
\hline 10 & sporadic & 16 \\
\hline 11 & sporadic & 16 \\
\hline 12 & sporadic & 16 \\
\hline 13 & sporadic & 16 \\
\hline 14 & focal & 16 \\
\hline 15 & focal & 16 \\
\hline 16 & diffuse & 16 \\
\hline 17 & diffuse & 16 \\
\hline 18 & diffuse & 18 \\
\hline 19 & diffuse & 18 \\
\hline \multicolumn{3}{|c|}{ invasive squamous cell carcinomas } \\
\hline 20 & negative & $16^{*}$ \\
\hline 21 & poor & $16 *$ \\
\hline 22 & sporadic & $16 *$ \\
\hline 23 & sporadic & 16 \\
\hline 24 & sporadic & $16 *$ \\
\hline 25 & focal & $16 *$ \\
\hline 26 & focal & 16 \\
\hline 27 & focal & 16 \\
\hline 28 & focal & 18 \\
\hline 29 & focal & 16 \\
\hline 30 & focal & 16 \\
\hline 31 & diffuse & 16 \\
\hline 32 & diffuse & 16 \\
\hline 33 & diffuse & 16 \\
\hline 34 & diffuse & 66 \\
\hline 35 & diffuse & 16 \\
\hline 36 & diffuse & 16 \\
\hline 37 & diffuse & 16 \\
\hline 38 & diffuse & 16 \\
\hline 39 & diffuse & 18 \\
\hline 40 & diffuse & $16+18$ \\
\hline
\end{tabular}

* confirmed by Southern blotting

thelium koilocytes or condyloma had been registered. In addition, in 11 samples of normal glandular and stromal cervical tissues and one sample of uterus body normal myometrium tissue which were obtained from patients with gynecological disorders $\mathrm{p} 16^{\mathrm{INK} 4 \mathrm{a}}$ was not expressed at all.

The predominant majority of invasive carcinoma samples were both high-risk HPV-positive and p16 $6^{\text {INK4a }}$-express- ing. However in 2 samples not expressing any p16 $16^{\text {INK4a }}$ or expressing it poorly high-risk HPV DNA sequences were detected by both PCR and Southern blot hybridization. These data are in a good agreement with those by Klaes et al., who described two samples of p16 INK4a-negative but HPV-positive cervical cancer [9]. Among CIN III samples which were stained in our experiments poorly or lacked any staining (table 2, samples 1-6) high risk HPVs were found in 6 out of 6 tested. As to CIN I and CIN II samples expressing p $16^{\mathrm{INK}} 4 \mathrm{a}$ in less than $1 \%$ of cells ( 1 data, samples $1-5$ and 10-14, respectively), we did not find any high-risk HPV-negative case in those groups either.

Thus there seem to exist dysplastic and neoplastic lesions of cervix uteri which do not overexpress the protein p16 ${ }^{\text {INK4a }}$ but harbor high-risk HPV DNA.

We confirm the data by Klaes et al. [9] that prolonged (for 7 years in our case) preservation of cervical carcinoma samples in paraffin blocks does not preclude the material from diffuse staining.

Monoclonal antibodies E6H4 originally described by Klaes et al [9] had been tested by those authors among a

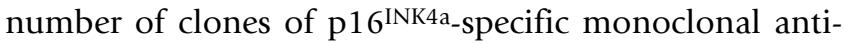
bodies. The following commercially available clones had been taken: 1). DCS-50.1/H4-NA29 (Oncogene Research Products, Cambridge, MA), 2). 375P (Biogenex Laboratories, San Ramon, CA), 3). ZJ11 and JC8 (NeoMarkers, Freemont, CA), 4) 05-418 (Upstate Biotechnology, Lake Placid, NY) and 5). J175-405 (PharMingen, San Diego, $\mathrm{CA}$ ). The results of the comparative experiments by Klaes at al [9] had demonstrated that clone E6H4 had turned out to be the most specific as inferred on the lowest level of unspecific staining on different tumor cell lines, both HPV-negative and positive. As in our experiments Klaes et al. [9] registered mainly cytoplasmic staining both in cells of permanent cell lines and in preneoplastic and carcinoma samples; an exclusive nuclear staining was not detected.

We observed strong p16 $16^{\text {INK4a }}$-positivity (sporadic or focal staining) in a comparatively small number of CIN I and CIN II samples (13-14\%). Among CINs III the portion of such samples increased up to $54,2 \%$, with diffuse staining in every sixth case.

The data we have obtained for CINs of all stages rather differ from the results by Klaes et al. [9]. All of CINs II and CINs III were stained as diffuse by Klaes et al. [9]. In the present study the group of CINs as a whole is much more heterogeneous. The reasons for those discrepancies are not quite clear yet. The population of Russian and Ukrainian patients whose materials were used in the present study was extremely heterogeneous with respect to age, 
Table 3: STAINING OF THE REFERENCE MATERIALS WITH pI6INK4a_SPECIFIC MONOCLONAL ANTIBODIES

\begin{tabular}{|c|c|c|c|c|c|c|}
\hline MATERIALS & number of samples & negative & poor & sporadic & focal & diffuse \\
\hline Normal tissues, including & 12 & 12 & - & - & - & - \\
\hline Uterus body (myometrium) & I & 1 & - & - & - & - \\
\hline $\begin{array}{l}\text { Stromal and glandular tissues of cervix } \\
\text { uteri }\end{array}$ & II & II & - & - & - & - \\
\hline
\end{tabular}

Table 4: THE SHARE OF pI6INK4a_NEGATIVE SAMPLES AMONG CERVICAL CARCINOMAS (LITERATURE DATA)

\begin{tabular}{|c|c|}
\hline Research group (reference) & The share (per cent) of p/61NK4a_negative samples \\
\hline & among adenocarcinomas: \\
\hline Lu et al, 1998 (7) & $17 / 40(42.5 \%)$ \\
\hline Sano et al, I998 (8) & $4 / 15$ (26.7\%) \\
\hline Milde-Langosch et al, $200 \mathrm{I}(10)$ & $8 / 58(13,8 \%)$ \\
\hline Klaes et al, 200I(9) & I/7 (I4.3\%) \\
\hline Saqi et al, 2002 (13) & $0 / 2(0 \%)$ \\
\hline Murphy et al, 2003 (14) & $0 / 2(0 \%)$ \\
\hline Negri et al, 2003 (I5) & $0 / 18(0 \%)$ \\
\hline Agoff et al, 2003 (16) & $2 / 7(28.6 \%)$ \\
\hline \multirow[t]{2}{*}{ Present study } & $0 / 5(0 \%)$ \\
\hline & among squamous cell carcinomas: \\
\hline Wong et al, 1997 (6) & $8 / 79(10.1 \%)$ \\
\hline Sano et al, 1998 (8) & $1 / 39(2.8 \%)$ \\
\hline Klaes et al, 2001 (9) & $\mathrm{I} / 53(1.9 \%)$ \\
\hline Sano et al, 2002 (I2) & $0 / 34(0 \%)$ \\
\hline Klaes et al, $2002(4)$ & $0 / 46(0 \%)$ \\
\hline Saqi et al, 2002 (13) & $0 / 1(0 \%)$ \\
\hline Murphy et al, 2003 (14) & $0 / 8(0 \%)$ \\
\hline Agoff et al, 2003 (I6) & $4 / 46(8.7 \%)$ \\
\hline Present study & $\mathrm{I} / 2 \mathrm{I}(4.8 \%)$ \\
\hline
\end{tabular}

nationality, etc. We cannot exclude that the discrepancies mentioned may be due to these factors as had been discussed earlier [26].

Nevertheless the coincidence between our results and the data by Klaes et al [9] concerning the general trend seems much more important: the increase of p16 $6^{\text {INK4a }}$ expression in dysplastic and neoplastic cervical epithelium in the course of progression.

This trend is especially evident in our study when negative cases only are taken into consideration. All 6 samples were p16 INK4a-negative in control group. Similar was the situation in the reference group: 12/12 negative. Among CINs I, CINs III and invasive carcinomas these indices made up $32 / 51(63 \%), 8 / 24(33 \%)$ and $1 / 26(4 \%)$ respectively.

The data presented herein allow us to conclude that hyperexpression of $\mathrm{p} 16^{\mathrm{INK} 4 \mathrm{a}}$ when detected immunohistochemically may be regarded as a marker of dysplastic and neoplastic lesions in cervical epithelium. Positive correlation between p16 INK4a expression and morphological stage of the disease on the same slide (when combined cases with both dysplastic and neoplastic lesions were found) also favors this inference.

In a number of recent communications immunochemical staining for p16 $6^{\mathrm{INK} 4 \mathrm{a}}$ was suggested to be performed on cytological smears [9,13-15]. Cytological approach has some advantages, so far as it enables a patient to avoid surgical intervention. That is why one may expect in the nearest future immunocytochemical version for detecting p16 ${ }^{\text {INK4a }}$ to become rather widely used not only as an addition to surgery but also for regular examinations in outpatient clinics. In this connection it seems important to estimate frequencies of a feasible false-negativity of the test.

Keeping in mind that dysplastic lesions of all stages frequently regress and do not convert into invasive cervical carcinomas [2], we summarized the data by different groups on the frequencies of $\mathrm{p} 16^{\mathrm{INK} 4 \mathrm{a}}$-negative invasive carcinoma samples (Table 4). We found that p16INK4a negative cervical adenocarcinomas had been detected 
with frequencies which had varied from $0 \%$ up to $42,5 \%$ while p16INK4a-negative squamous cell carcinomas - with frequencies that had not exceeded 10,1\%. Substantial variability of the data may be due to small numbers of samples analyzed (in some of the studies), to utilization of different types of monoclonal antibodies, to different criteria used by different research groups for the results interpretation, etc.

It seems important to realize the proper place of immunocyto-/ immunohistochemical analysis of p16 ${ }^{\mathrm{INK}} 4 \mathrm{a}$ expression among previously developed tests for early detection of cervical carcinomas. In this connection the following points deserve mentioning. A pathologist in the course of common histological investigation usually registers some morphologic features such as zones of active mitotic divisions, multipolar mitoses, vicinity of condilomas and other formations. However when performing an immunocytochemical analysis on a smear a cytologist cannot bring in a correlation with morphological structure results of staining with $\mathrm{p} 16^{\mathrm{INK} 4 \mathrm{a}}$-specific antibodies in separate cells. According to the results of the present study about $33 \%$ of CINs III as well as about $5 \%$ of invasive squamous cell carcinomas of cervix uteri do not differ from normal cervical epithelium with respect to p16 INK4a expression. Thus immunochemical staining for p16 $6^{\text {INK4a }}$ (in both cyto- and histochemical versions) does not seem to be the approach that can help to fully overcome absolutely all existing ambiguities of cervical cancer early diagnostics.

As to possible sources of false positivity of immunochemical detection of the protein p16 ${ }^{\text {INK4a }}$ the study by Agoff et al [16] deserve mentioning. According to this communication in 10 out of 10 endometrial biopsy samples studied endometrial cells were positively stained with the p16 INK4a - specific antibody E6H4. So far as endometrial cells may occur on vaginal smears the test does not seem to enable one to fully avoid false positivity.

\section{Conclusions}

Overexpression of the protein p16 INK4a encoded by tumor suppressor gene INK4a is a characteristic of displastic and neoplastic alterations of cervical epithelium. The portion of p16 $16^{\mathrm{INK} 4 \mathrm{a}}$-positive samples increases in the following row: CIN I - CIN II - CIN III - invasive carcinoma. All stages of CINs and carcinomas analysed are heterogeneous with respect to p16 INK4a expression: side by side with the samples which expressed p16 INK4a in $25 \%$ of cells or more we detected samples which were stained poorly or lacked any staining. According to the data we present herein p16 INK4a-negative cervical neoplasms and carcinomas do exist. Thus the lack of p16 ${ }^{\text {INK4a }}$-positive cells in samples from different types of cervical lesions should not be regarded as a sufficient reason for excluding a patient from the high-risk group. Despite this as far as normal cer- vical epithelium is p16 ${ }^{\mathrm{INK}} 4 \mathrm{a}-$ negative and the ratio p16 INK4a-positive/ p16 INK4a-negative samples increases at the advanced stages of CINs and carcinomas application of immunohisto-/cytochemical test for p16 $6^{\text {INK4a }}$ may be regarded as an additional (optional) test for early detection of precancerous lesions in cervical epithelium.

\section{Competing interests}

none declared

\section{Author's contributions}

F.K., D.S., G.V. and G.F. contributed to study conception and design; E.K. and A.B. delt with sample obtaining and preliminary diagnosis; Yu.A., G.F. and V.E. were independent pathologists who confirmed the diagnosis; G.V., L.Z. and D.G. performed immunohistochemical staining and analysis; A.B. carried out HPV typing; G.V. drafted the manuscript. All authors read and approved the final version.

\section{Additional material}

\section{Additional File 1}

Data on high risk HPV genome detection by PCR in CIN I and CIN II samples. the data are presented on high-risk HPV genetic material detection in 9 CIN I and 9 CIN II samples.

Click here for file

[http://www.biomedcentral.com/content/supplementary/14712407-4-58-S1.xls]

\section{Acknowledgements}

The authors thank Drs N.P.Kisseljova and N.N.Mazurenko for promoting discussion of the results. We appreciate assistance of Drs. A.Petrov and A.Petrenko in preparing the manuscript. The work was supported in part by FIRCA grant NIH 0600-070-c223 as well as by the Russian Foundation of Basic Science (grant No 02-04-4827I) and Russian Ministry of Science (grant N 1877).

\section{References}

I. Zaridze DG: Epidemiology and etiology of malignant tumors. In Carcinogenesis Edited by: Zaridze DG. Moscow: Nauchny Mir; 2000:21-56. Russian

2. Zur Hausen H: Papillomaviruses and cancer: from basic studies to clinical applications. Nature Reviews Cancer 2002, 2:342-350.

3. Papanicolaou GN: Science 1942, 95:438-439.

4. Klaes R, Benner A, Friedrich T, Ridder R, Herrington S, Jenkins D, Kurman RJ, Schmidt D, Stoler M, von Knebel Doeberitz M: P I 6 INK4a immunohistochemistry improves interobserver diagnosis of cervical intraepithelial neoplasia. Am J Surg Pathol 2002, 26:1389-1399.

5. Walboomers JMM, Melkert PWJ, Van Den Brule AJC, Snijders PJF, Meijer CJLM: Application of polymerase chain reaction for screening of Human Papillomaviruses in cytopathologies of the cervix uteri. In: Molecular Diagnostic Pathology. A practical approach Edited by: Herrington CS, McGee J. Moscow: Mir; 1999:474-495.

6. Wong YF, Cheung TK, Chung TKH, Chan MKM, Chang AMZ: Expression of p I6INK4a and Rb genes in cervical neoplasm. J Lower Genital Tract Dis 1997, I:240-244. 
7. Lu X, Toki T, Konishi I, Nikaido T, Fujii S: Expression of p2 I WAFI/ CIPI in adenocarcinoma of the uterine cervix: a possible immunohistochemical marker of a favourable prognosis. Cancer 1998, 82:2409-24I7.

8. Sano T, Oyama T, Kashiwabara K, Fukuda T, Nakajima T: Expression status of $\mathrm{pl} 6$ protein is associated with human papillomavirus oncogenic potential in cervical and genital lesions. $\mathrm{Am} J$ Pathol 1998, 153:174I-1748.

9. Klaes R, Friedrich T, Spitkovsky D, Ridder R, Rudy W, Petry U, Dallenbach-Hellweg G, Schmidt D, von Knebel Doeberitz M: Overexpression of p I6INK4a as a specific marker for dysplastic and neoplastic epithelial cells of the cervix uteri. Int J Cancer 200I, 92:276-284.

10. Milde-Langosch K, Riethdorf S, Kraus-Poppinghaus A, Riethdorf L, Loning $\mathrm{T}$ : Expression of cyclin-dependent kinase inhibitors p I $6{ }^{\text {MTSI}}$, P2 I WAFI, and P27 KIPI in HPV-positive and HPV-negative cervical adenocarcinomas. Virchows Arch 200I, 439:55-6I.

1I. Volgareva GM, Zavalishina LE, Frank GA, Andreeva YuYu, Petrov AN Kisseljov FL, Spitkovsky DD: Expression of protein marker p I 6INK4a in uterine cervical cancer. Arkh Patol 2002, 64(I):22-24 Russian

12. Sano T, Masuda N, Oyama T, Nakajima T: Overexpression of p 16 and pI4ARF is associated with human papillomavirus infection in cervical squamous cell carcinoma and dysplasia. Pathol Int 2002, 52:375-83.

13. Saqi A, Pasha TL, McGrath CM, Yu GH, Zhang P, Gupta P: Overexpression of p/6INK4a in liquid-based specimens (SurePath trade mark) as marker of cervical dysplasia and neolpasia. Diagn Cytopathol 2002, 27:365-370.

14. Murphy N, Ring M, Killalea AG, Uhlmann V, O'Donovan M, Mulcahy F, Turner M, McGuinness E, Griffin M, Martin C, Sheils O, O'Leary J]: PI 6INK4a as a marker for cervical dyskaryosis: CIN and CGIN in cervical biopsies and ThinPrep smears. J Clin Pathol 2003, 56:56-63.

15. Negri G, Egarter-Vigl E, Kasal A, Romano F, Haitel A, Mian C: $P$ I INK $^{\text {IN }}$ is a useful marker for the diagnosis of adenocarcinoma of the cervix uteri and its precursors. Am J Surg Pathol 2003, 27: $187-193$

16. Agoff SN, Lin P, Morihara J, Mao C, Kiviat NB, Koutsky LA: PI 6INK4a expression correlates with degree of cervical neoplasia: a comparison with $\mathrm{Ki}-67$ expression and detection of high-risk HPV types. Mod Pathol 2003, 16:665-673.

17. Serrano $M$, Hannon GJ, Beach $D$ : A new regulatory motif in cellcycle control causing specific inhibition of cyclin D/CDK4. Nature 1993, 366:704-707.

18. Ruas M, Peters G: The pl6INK4a/CDKN2A tumor suppressor and its relatives [review]. Biochim Biophys Acta 1998, 1378:FII5-FI77.

19. Dyson N, Howley PM, Munger K, Harlow E: The human papilloma virus- 16 E7 oncoprotein is able to bind to the retinoblastoma gene product. Science 1989, 243:934-937.

20. Tam SW, Shay JW, Pagano M: Differential expression and cell cycle regulation of the cyclin-dependent kinase 4 inhibitor p 16INK4a. Cancer Res 1994, 54:5816-5820.

21. Khleif SN, DeGregori J, Jee CL, Otterson GA, Kaye FJ, Nevins JR, Howley PM: Inhibition of cyclin D-CDK4/CDK6 activity is associated with an E2F-mediated induction of cyclin kinase inhibitor activity. Proc Natl Acad Sci USA 1996, 93:4350-4354.

22. Geradts J, Kratzke R, Niehans GA, Lincoln CE: Immunohistochemical detection of the cyclin-dependent kinase inhibitor 2/multiple tumor suppressor gene I (CDKN2/MTSI) product p I 6 INK4a in archival human solid tumors: correlation with retinoblastoma protein expression. Cancer Res 1995, 55:6006-60II.

23. Kratzke RA, Greatens TM, Rubins JB, Maddaus MA, Niewoehner DE Niehans GA, Geradts J: Rb and pI 16 INK4a expression in resected non-small cell lung tumors. Cancer Res 1996, 56:3415-3420.

24. Lowe SW, Sherr CJ: Tumor suppression by Ink4a-Arf: progress and puzzles. Curr Opin Genet Dev 2003, I3:77-83.

25. Samoylova EV, Shaikhaiev GO, Petrov SV, Kisseljova NP, Kisseljov FL: HPV infection in cervical-cancer cases in Russia. Int J Cancer 1995, 6 I: I-5.

26. Kisseljov FL, Kisseljova NP, Kobzeva VK, Gritsko TM, Semenova LA, Pavlova LS, Klaes R, von Knebel Doeberitz M: State of Human Papilloma virus DNA in Cervical Carcinomas. Molecular Biology 200I, 35:399-404.

\section{Pre-publication history}

The pre-publication history for this paper can be accessed here:

http://www.biomedcentral.com/1471-2407/4/58/prepub
Publish with Biomed Central and every scientist can read your work free of charge

"BioMed Central will be the most significant development for disseminating the results of biomedical research in our lifetime. "

Sir Paul Nurse, Cancer Research UK

Your research papers will be:

- available free of charge to the entire biomedical community

- peer reviewed and published immediately upon acceptance

- cited in PubMed and archived on PubMed Central

- yours - you keep the copyright 